\title{
Biological control of potato soft rot caused by Erwinia carotovora subsp. carotovora
}

\author{
Ehab A. Salem ${ }^{1}$ and Yasser M. Abd El-Shafea ${ }^{2^{*}}$ (D)
}

\begin{abstract}
Four bioagents, Bacillus subtilis, Pseudomonas fluorescence, P. aeruginosa, and Streptomyces spp., were used in vitro and in vivo against two pathogenic isolates of Erwinia carotovora subsp. carotovora (Ecc1 and Ecc2), the causal agent of potato soft rot. In vitro Streptomyces spp. showed the strongest effect against Ecc1 and Ecc2 and gave the highest values of the inhibition zones, being 37 and $40 \mathrm{~mm}$, respectively followed by $P$. fluorescence, $B$. subtilis, and $P$. aeruginosa, where the inhibition zones reached, respectively, 32, 28, and $24 \mathrm{~mm}$ against Ecc 1 and 35, 29, and $26 \mathrm{~mm}$ against Ecc2. Also, these results confirmed those of the in vivo experiment (in pots) since Streptomyces spp. bioagent exhibited the lowest number of infected tubers followed by P. fluorescence, B. subtilis, and P. aeruginosa, respectively, against the two isolates Ecc1 and Ecc2. Also, disease severity of soft rot caused by each of the two isolates, Ecc1 and Ecc2, was decreased by using bioagents, and the lowest disease severity values were obtained by using Streptomyces spp., P. fluorescence, B. subtilis, and P. aeruginosa, respectively.
\end{abstract}

Keywords: Biological control, Erwinia carotovora subsp. carotovora, Potato soft rot

\section{Background}

Potato, Solanum tuberosum L., is one of the most important food and crops worldwide, and its production in developing countries increased at the rate of $2.8 \%$ annually (CIP 1995). Bacterial soft rot and black leg are probably the most serious diseases in terms of crop losses. Infection by late blight and dry rot pathogens is significant, not only because of the damage they cause to potato tubers, but also because they provide potential avenues of entrance of secondary invasion by Erwinia carotovora subsp. carotovora and E. carotovora subsp. atroseptica (Lui et al. 2005).

Microorganisms that can grow in potato rhizosphere are ideal to be used as biocontrol agents, since the rhizosphere provides the front line defense for roots and tubers against attack by pathogens (Kabeil et al. 2008).

Pseudomonas fluorescence, Bacillus subtilis, and E. herbicola showed activity against E. carotovora subsp. carotovora (Vanneste and Yu et al. 1996). Streptomyces is a well-known genus of the order Actinomycetales family. They usually inhabit soil and commonly enhance soil fertility. These prokaryotes have characteristics which make

\footnotetext{
* Correspondence: yasser_773@hotmail.com

${ }^{2}$ Regional Center for Food and Feed (RCFF), Agricultural Research Center (ARC), P.O. BOX: 588 Orman, Giza, Egypt

Full list of author information is available at the end of the article
}

them useful as biocontrol agents against bacterial plant pathogens (Keiser et al. 2000). Biological control is considered as one of the most important methods to control bacterial soft rot disease in potato tubers (Algeblawi and Adam 2013).

In this study, we aimed to evaluate in vitro and in vivo effectiveness of four bioagents, B. subtilis, P. fluorescence, $P$. aeruginosa, and Streptomyces spp., against E. carotovora subsp. carotovora (Ecc1 and Ecc2), the causal agent of potato soft rot.

\section{Materials and methods}

\section{Potato tubers}

Potato seeds (Solanum tuberosum L., Diamante variety) were obtained from the Horticulture Department, Agricultural Research Center, Giza, Egypt.

\section{Bacterial strains}

Two isolates of E. carotovora subsp. carotovora (Ecc1 and Ecc2) WPP17 were obtained from the Bacterial Disease Research Department, Plant Pathology Research Institute, Agricultural Research Center, Giza, Egypt. 


\section{Antagonistic organisms}

The antagonistic bacteria and actinomycetes (B. subtilis, P. fluorescence, P. aeruginosa, and Streptomyces spp.) were obtained from Bacteriological Lab, Faculty of Science, Zagazig University, Egypt.

\section{Sensitivity of E. carotovora subsp. carotovora isolates to antagonistic microorganisms (in vitro)}

Antagonistic effect of B. subtilis, P. fluorescence, P. aeruginosa, and Streptomyces spp. on two isolates of E. carotovora subsp. carotovora (Ecc1 and Ecc2) was studied. The suspension representing each of the two isolates of $E$. carotovora subsp. carotovora $\left(1 \times 10^{5} \mathrm{CFU} / \mathrm{cm}^{3}\right)$ was spread on the surface of the Czabe-dox agar media in petri dishes by a sterilized L-shaped glass rod spreader followed by placing a 7-mm diameter agar disk cut from the margin of a culture grown in a plate on which the biocontrol strain had been grown for $48 \mathrm{~h}$ at $28^{\circ} \mathrm{C}$ for bacteria and for 7 days for actinomycetes in the center of each plate. Inhibition zone diameter of two isolates of $E$. carotovora subsp. carotovora (Ecc1 and Ecc2) was measured after incubation at $28^{\circ} \mathrm{C}$ for $48 \mathrm{~h}$, and mean value of three replicates was calculated.

\section{Effect of bacterial bioagents on infected potato tubers with} E. carotovora subsp. carotovora (in vivo)

Pots $(30 \mathrm{~cm}$ diameter) were sterilized by soaking in formalin (5\%) for $5 \mathrm{~min}$ and left for 1 week to get rid of the poisonous effect of formalin. Pots were filled with autoclaved soil (autoclaved for $3 \mathrm{~h}$ for three successive days). Inoculation of both bioagents or pathogenic two isolates of E. carotovora subsp. carotovora (Ecc1 and Ecc2) was prepared by growing each bacterium in a conical flask containing $200 \mathrm{ml}$ autoclaved sucrose-peptone liquid medium incubated at $30{ }^{\circ} \mathrm{C}$ for $48 \mathrm{~h}$. Actinomycetes inoculum was prepared by growing Streptomyces sp. in flasks containing autoclaved starch nitrate liquid medium and incubated at $30^{\circ} \mathrm{C}$ for 7 days.

Ten potato tubers (Diamante) were washed with tap water and surface sterilized by ethyl alcohol $70 \%$. The antagonistic bacteria or actinomycetes $\left(2 \times 10^{8} \mathrm{CFU} / \mathrm{ml}\right)$ were mixed with $1 \%(W / V)$ carboxymethyl cellulose as sticker agent for $1 \mathrm{~h}$ (Anuratha and NSS 1990). Tubers of potato after surface sterilization were soaked for $1 \mathrm{~h}$ in the above mixture. These tubers were left overnight in jars for drying, then cultivated in potted soil inoculated by the two isolates of E. carotovora subsp. carotovora (Ecc1 and Ecc2) each alone; the treatments were as the follows:

1. Control (untreated tubers planted in sterilized soil),

2. Tubers coated by each of the antagonistic microorganisms alone (bacteria or actinomycetes) and planted in soil,
3. Tubers planted in soil inoculated by E. carotovora subsp. carotovora (Ecc1),

4. Tubers planted in soil inoculated by E. carotovora subsp. carotovora (Ecc2),

5. Tubers coated by each of the antagonistic bacteria or actinomycetes and planted in soil inoculated by E. carotovora subsp. carotovora (Ecc1)

6. Tubers coated by each of the antagonistic bacteria or actinomycetes and planted in soil inoculated by E. carotovora subsp. carotovora (Ecc2).

Three tubers were planted in each pot, and five pots were used as replicates for each treatment; the pots left in a glass house at $28 \pm 2{ }^{\circ} \mathrm{C}, 80 \%$ humidity, and irrigation were carefully carried out. The percentages of infection as well as healthy survivals and disease severity of the disease were recorded at the end of the experiment according to Chastanger and Ogawa (1979) based on visual inspection of each tuber infection. Infected fruits were placed in one of five categories:

$$
\begin{aligned}
& 0=\text { superficial flack (no rot) } \\
& 1=1-24 \% \text { of the surface decayed } \\
& 2=25-49 \% \text { of the surface decayed } \\
& 3=50-74 \% \text { of the surface decayed } \\
& 4=75 \% \text { or more of the surface decayed }
\end{aligned}
$$

The decay index (DI) for each treatment was obtained as follows:

$$
\mathrm{DI}=\frac{\text { Sum }(\text { number of tuber per category } \times \text { category number }}{\text { Total number of infected tuber }}
$$

\%severity of infection $=(\mathrm{DI} / 4 \times 100)$

\section{Experimental design and statistical analysis}

All treatments in this study were arranged in a complete randomized design. The obtained data were subjected to analysis of variance using the general linear module procedure of Anonymous (1985), where appropriate treatment means were separated using Duncan's multiple range test (Duncan 1955) and all percentages were transferred to the analysis before statistical analysis.

\section{Results and discussion}

In vitro antagonistic effect of bacterial bioagents on two isolates of $E$. carotovora subsp. carotovora

Data in Table 1 show that in vitro antagonistic activity of Streptomyces spp. exhibited the highest inhibition zones (mm) against the two isolates of E. carotovora subsp. carotovora (Ecc1 and Ecc2), being 37 and $40 \mathrm{~mm}$, respectively, followed by $P$. fluorescence $(32 \mathrm{~mm}$ and $35 \mathrm{~mm}$ ), 
Table 1 In vitro antagonistic activity of Bacillus subtilis, Pseudomonas fluorescence, Pseudomonas aeruginosa, and Streptomyces spp. with two isolates of Erwinia carotovora subsp. carotovora (Ecc1 and Ecc2)

\begin{tabular}{|c|c|c|}
\hline \multirow[t]{2}{*}{ Treatment } & \multicolumn{2}{|l|}{ Inhibition zone (mm) } \\
\hline & Erwinia carotovora (Eccl) & Second strain (Ecc2) \\
\hline Bacillus subtilis & $28 \pm 0.47^{e}$ & $29 \pm 0.57^{e}$ \\
\hline $\begin{array}{l}\text { Pseudomonas } \\
\text { fluorescence }\end{array}$ & $32 \pm 0.35^{d}$ & $35 \pm 0.45^{c}$ \\
\hline P. aeruginosa & $24 \pm 0.47^{9}$ & $26 \pm 0.52^{f}$ \\
\hline Streptomyces spp. & $37 \pm 0.35^{b}$ & $40 \pm 0.42^{\mathrm{a}}$ \\
\hline
\end{tabular}

Various superscript letters indicate significant differences (Duncan, $p<0.05$ )

respectively, but $B$. subtilis and $P$. aeruginosa exhibited the lowest values of inhibition zones against the two isolates of E. carotovora subsp. carotovora (Ecc1 and Ecc2), being $28,29,24$, and $26 \mathrm{~mm}$, respectively.

\section{In vivo antagonistic effect of bacterial bioagents against} the two isolates of E. carotovora subsp. carotovora

Data in Table 2 show that Streptomyces spp. was the most potent bioagent against the two isolates of E. carotovora subsp. carotovora (Ecc1 and Ecc2) since they gave the lowest numbers of infected tubers. Meanwhile, the percentage of infected tubers recorded $10 \%$ and $5 \%$ for Ecc1 and Ecc2, respectively, followed by $P$. fluorescence which percentage recorded for infected tubers was 15\% for two isolates (Ecc1 and Ecc2), respectively. B. subtilis reduced percentage of infected tubers to $30 \%$ and $25 \%$ (Ecc1 and Ecc2), respectively. But P. aeruginosa reduced percentage of infected tubers to $35 \%$ and $40 \%$ for Ecc1 and Ecc2, respectively.

Data in Fig. 1 show the severity of soft rot caused by the first isolate (Ecc1) of E. carotovora subsp. carotovora was decreased from 5 to $0.5 \%$ by using Streptomyces spp. as bioagent. Meanwhile, disease severity was also decreased due to using other bioagents from 5 to $0.75,1.5$, and 1.75 due to using $P$. fluorescence, $B$. subtilis, and $P$. aeruginosa, respectively. Also by using the second isolate of E. carotovora subsp. carotovora (Ecc2), the disease severity was decreased from 5 to $0.5,0.75,1.25$, and 2 due to using Streptomyces spp., P. fluorescence, B. subtilis, and P. aeruginosa, respectively.

The obtained results show that soft rot disease caused by the two isolates of $E$. carotovora subsp. carotovora (Ecc1 and Ecc2) can be biologically controlled by Streptomyces spp., B. subtilis, $P$. fluorescence, and $P$. aeruginosa, respectively. These results are in agreement with those recorded by Ryan et al. (2001) who reported that B. subtilis GBO3 and B. amyloliquefaciens IN937a were able to promote plant growth indirectly through induced systematic resistance (ISR); this happens through secretion of volatiles which in turn activate an ISR pathway in Arabidopsis seedlings challenged with the soft rot pathogen $E$. carotovora subsp. carotovora. Lemessa and Zeller (2007) showed that using antagonistic isolates like $B$. subtilis and P. macerans has potential in potato bio protection or as a part of an integrated disease management package for bacterial diseases. Seaf Elyazel (2008) revealed that Streptomyces spp. (gram-positive filamentous bacteria) can produce and secrete a biologically active compound including antibiotics, ionophores, hydrolytic enzymes (protease, nuclease, lipase, and a variety of enzymes hydrolyzing polysaccharides), and enzyme inhibitors. These characteristics make Streptomyces spp. attractive candidates for biological control agents against soil-borne plant pathogens. Salem and Askora (2012) confirmed that the brown rot disease in Egyptian potato tubers caused by Ralstonia solanacearum can biologically be controlled by using the bioagents $P$. fluorescence, B. subtilis, $P$. aeruginosa, and Streptomyces spp., and the latter gave the effective results in controlling the brown rot in

Table 2 In vivo biological control of potato soft rot caused by two isolates of Erwinia carotovora subsp. carotovora by using Bacillus subtilis, Pseudomonas fluorescence, Pseudomonas aeruginosa, and Streptomyces spp.

\begin{tabular}{llll}
\hline Treatment & No. of healthy tubers & No. of infected tubers & Infection \% to control \\
\hline Tubers only (control) & 20 & 0 & 0 \\
Tubers + Ecc1 & 0 & 20 & 100 \\
Tubers + Ecc1 + B. subtilis & 14 & 6 & 30 \\
Tubers + Ecc1 + P. fluorescence. & 17 & 3 & 15 \\
Tubers + Ecc1 + P. aeruginosa & 13 & 7 & 35 \\
Tubers + Ecc1 + Streptomyces spp. & 18 & 2 & 10 \\
Tubers + Ecc2 & 0 & 20 & 100 \\
Tubers +Ecc2 + B. subtilis & 15 & 5 & 25 \\
Tubers + Ecc1 + P. fluorescence & 17 & 3 & 15 \\
Plant + Ecc1 + P. aeruginosa & 12 & 8 & 40 \\
Plant + Ecc1 + Streptomyces spp. & 19 & 1 & 5 \\
\hline
\end{tabular}




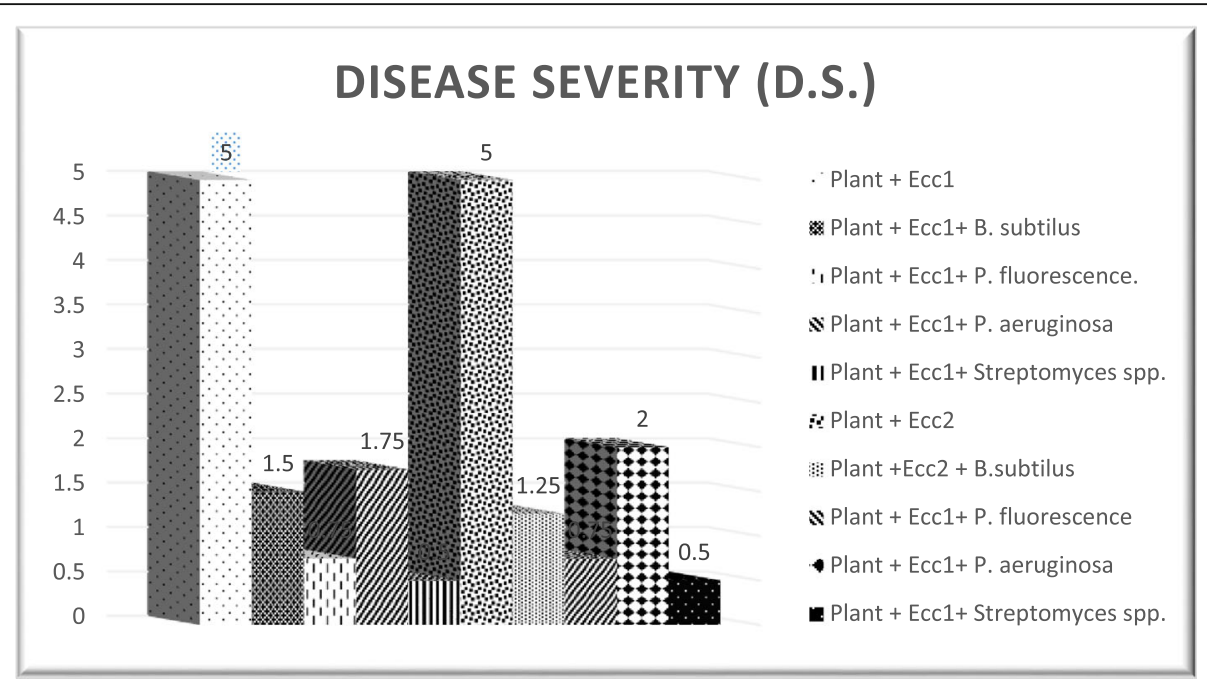

Fig. 1 Disease severity of soft rot due to using Streptomyces spp., Bacillus subtilis, Pseudomonas fluorescence, and Pseudomonas aeruginosa

potato tubers. Algeblawi and Adam (2013) reported that the bioagents, i.e., P. fluorescence, B. subtilis, and B. thuringiensis, reduced soft rot disease in potato tubers caused by $E$. carotovora subsp. carotovora in pot experiment. The best results were obtained when isolates of $P$. fluorescence and B. subtilis were applied against E. carotovora subsp. carotovora compared to control treatment.

\section{Conclusion}

The results of the current study indicated that the usage of four bacteria as bioagents was effective in decreasing the severity of E. carotovora subsp. carotovora (Ecc1 and Ecc2) infection in potato tubers. It is worthy to note that Streptomyces spp. showed more pronounced effects against E. carotovora subsp. carotovora (Ecc1 and Ecc2) in either in vivo or in vitro studies than the other three bacterial bioagents.

\section{Acknowledgements}

The authors are grateful to the Horticulture Department, Agricultural Research Center, Giza, Egypt; Bacterial Disease Research Department, Plant Pathology Research Institute, Agricultural Research Center, Giza, Egypt; and Bacteriological Lab, Faculty of Science, Zagazig University, Egypt, for the facilities provided for conducting the study.

\section{Funding}

We are working on our own fund.

\section{Availability of data and materials}

The dataset supporting the conclusions of this article are included within the article.

\section{Authors' contributions}

First author EA is responsible for the implementation and conception or design of the experimental work and for designing and supervising the study. Second author YM is responsible for revising the paper scientifically, checking analysis, and interpreting data. Both authors read and approved the final manuscript.
Ethics approval and consent to participate Not applicable

\section{Consent for publication}

Not applicable

\section{Competing interests}

The authors declare that they have no competing interests.

\section{Publisher's Note}

Springer Nature remains neutral with regard to jurisdictional claims in published maps and institutional affiliations.

\section{Author details}

${ }^{1}$ National Center for Radiation Research and Technology (NCRRT), Atomic Energy Authority, P.O. BOX: 8029, Nasr City, Egypt. ${ }^{2}$ Regional Center for Food and Feed (RCFF), Agricultural Research Center (ARC), P.O. BOX: 588 Orman, Giza, Egypt.

Received: 10 June 2018 Accepted: 19 November 2018 Published online: 03 December 2018

\section{References}

Algeblawi A, Adam F (2013) Biological control of Erwinia carotovora subsp. carotovora by Pseudomonas fluorescens, Bacillus subtilis and Bacillus thuringiensis. International Journal of Chemical, Environmental \& Biological Sciences (IJCEBS) volume 1(5):ISSN2320-ISSN4079

Anonymous (1985) SAS "Statistical Analysis System": SAS/STAT user's guide: statistics, version 6. 0.3 Edition. SAS Institute IC, Cary, N. C. USA

Anuratha CS, NSS G (1990) Plant Soil 124:109-116

Chastanger GA, Ogawa JM (1979) A fungicide wax treatment to suppress Botrytis cinerea and protect fresh market tomatoes. Phytopathology 69:59-63

CIP (1995) The International Potato Center, Prog. Report, 1993-94, Lima, Peru, pp 192. http://cipotato.org/wp-content/uploads/1993/01/253412692-CIP-ProgramReport-1993-1994.pdf

Duncan DB (1955) Multiple range and multiple F tests. Biometrics 11:1-42

Kabeil SS, Lashin SM, El-Masry MH, El-Saadani MA, Abd- Elgawad MM, Aboul-Einean AM (2008) American-Eurasian J. Agric Environ Sci 4(1):44-54

Keiser T, Bibb MJ, Buttner MJ, Chater KF, Hopwood DA (2000) Practical Streptomyces genetics. the John Inns Foundation, crows, Norwich, England, pp 1-21

Lemessa F, Zeller W (2007) Biol Control 42:336-344 
Lui LH, Vikram A, Abu-Nada Y, Kushalappa AC, Raghavan GSV, Al-Mughrabi K (2005) Volatile metabolic profiling for discrimination of potato tubers inoculated with dry and soft rot pathogens. Amer J of Potato Res 82:1-8 Ryan PR, Delhaize E, Jones DL (2001) Annu Rev Plant Physiol Plant Mol Biol 52: $527-560$

Salem EA, Askora A (2012) Biological control of the Egyptian brown rot in potato (Solanum tuberosum L.). Isotope \& Rad Res 44(3):671-678

Seaf Elyazel HAM (2008) Studies on potato brown rot disease under Egyptian conditions, M.Sc. Thesis, Agricultural Botany and Plant Pathology Dept. Faculty of Agriculture Zagazig University, Egypt

Vanneste, JL and Yu J (1996). Biological control of fire blight using Erwinia herbicola Eh252 andPseudomonas fluorescensA506 separately or in combination. Acta Hortic 411:351-353

Submit your manuscript to a SpringerOpen ${ }^{\odot}$ journal and benefit from:

- Convenient online submission

Rigorous peer review

- Open access: articles freely available online

High visibility within the field

- Retaining the copyright to your article

Submit your next manuscript at $\boldsymbol{\nabla}$ springeropen.com 